\title{
Evaluations of CMIP5 simulations over cropland
}

\author{
Min $\mathrm{Xu}^{a}$ and Forrest $\operatorname{Hoffman}^{a}$ \\ ${ }^{a}$ Climate Change Science Institute, Oak Ridge National Laboratory
}

\begin{abstract}
Cropland is one of major sources of carbon lost to the atmosphere and directly contributes to the emissions of greenhouse gases. There is, however, large potential for cropland to reduce its carbon flux to the atmosphere and sequester soil carbon through conservative agriculture management including no-tillage, perennial and/or deep root crops, irrigation, and organic fertilization etc. But these estimations on carbon emissions and sequestrations over cropland under future climate changes and variability remain largest uncertain among all other terrestrial biomes. Global climate and earth system models are an effective tool to study the cropland responses and feedbacks to present and future climate, yet most models in the latest couple model intercomparsion project phase 5 (CMIP5), generally treat cropland similarly as grassland with tuned parameters and do not account for realistic crop phenology, physiology, and management. In this study, we will evaluate the limitations and deficiencies of the CMIP5 models without process-based crop growth models over cropland by comparing their simulations against FLUXNET observations at eight cropland sites. The results show that: (1) the observed and simulated annual cycles generally are not consistent in either phase or amplitude; (2) the MPI and IPSL model families have better skills in the annual cycles of gross primary product (GPP), net ecosystem production (NEP), and terrestrial ecosystem respiration (TER) than other models at the corn/soybean and cereal sites respectively; (3) none of the CMIP5 models successfully simulate the observed two-peak pattern in the annual cycles of sensible heat fluxes at the corn/soybean sites; (4) the simulated GPPs and NEPs of the CESM1, BCC model families and NorESM1-M are much smaller than the observations for entire year; (5) model members from same model family normally simulate similar annual cycles both in phase and magnitude, but the model members from the CESM1 model family with different atmospheric models have different annual cycles; (6) the biases both in phases and magnitudes of annual cycles for the biogeochemical variables (GPP, NEP and TER) are generally larger than those biogeophysical variables (sensible and latent heat fluxes). Because of the above limitations and deficiencies of CMIP5 simulations over cropland, it is essential to incorporate process-based crop growth models into ESMs to improve the model physics and performance over cropland.
\end{abstract}

Keywords: CMIP5, Cropland, Model evaluation

\section{INTRODUCTION}

Cropland shares a large portion of the Earth's total land area (about $11 \%$ globally ${ }^{1,2}$ and $20 \%^{3}$ ) over United States and is likely continuously expanding to meet increasing demands in food, fibre and energy due to a growing population..$^{2,4,5}$ It is estimated that the global crop production needs to double by 2050 to meet the projected demands, ${ }^{6}$ this goal, however, seems unable to be reached based on the growth rate derived from the historical yield trends. ${ }^{7}$ The Food and Agriculture Organization estimates that more than $10 \%$ and $20 \%$ in developed and developing countries respectively, the projected growth in crop production by 2050 could be attributed to the land expansion while the remaining growth comes from the increased yield and cropping intensity due to future technology advance. ${ }^{8}$

Moreover, cropland plays an important role in global carbon cycle and is one of major contributors to global greenhouse gas (GHG) emissions. ${ }^{2}$ It is responsible for approximately $25 \%, 50 \%$, and $75 \%$ of annual anthropogenic emissions of carbon, methane, and nitrous oxide to the atmosphere respectively. ${ }^{9}$ However, changing agriculture management practices including irrigation, tillage and mulch, and covered, perennial, deep root crops may have large potential to mitigate the cropland GHG emissions. ${ }^{10,11}$ Nonetheless these estimations over cropland remain largest uncertain among all other terrestrial biomes. ${ }^{12}$

Corresponding Author: Dr. Min Xu, Computer Science \& Mathematics Division, Climate Change Science Institute (CCSI), Oak Ridge National Laboratory, Oak Ridge, TN, USA, Email: minxu@climatemodeling.org

Remote Sensing and Modeling of Ecosystems for Sustainability XII, edited by Wei Gao,

Ni-Bin Chang, Proc. of SPIE Vol. 9610, 961003 - @ 2015 SPIE

CCC code: $0277-786 X / 15 / \$ 18 \cdot$ doi: $10.1117 / 12.2192586$

Proc. of SPIE Vol. $9610961003-1$ 
Therefore, it is necessary to study the cropland responses and feedbacks to global and regional climate under future climate changes and variability in order to secure our food supply and mitigate the GHG emissions. Generally global circulation and climate models (GCMs) and earth system models (ESMs) are used to study the crop-climate interplays by simulating the comprehensively biogeophysical and biogeochemical processes. But there still remain large uncertainties in these model results due to the complex nature of climate systems and their closely interactions with human activities. ${ }^{13-15}$ More importantly most GCMs and ESMs such as those models in the fifth phase of the coupled model intercomparison project (CMIP5) do not include process-based crop growth models (CGMs) with comprehensive physiology and phenology and they generally treat crop in a similar way as grass with tuned model parameters. This simple approach will cause large biases and uncertainties as crop management and phenology largely affect crop growth and development, as well as carbon-nitrogen cycles over croplands.

Some ESMs began to incorporate CGMs into their land and carbon cycle model components recently. ${ }^{16-22}$ Due to the lacks of the global coverage of credible crop management data including planting, harvesting, irrigation, fertilization, and crop type and variety, these models generally need to be calibrated using the observed yields or other observations and therefor still have large uncertainties and biases in their future predictions. ${ }^{21}$

Hence it is necessary and essential to evaluate the skills of the ESMs on surface carbon, water and energy exchanges over cropland. As a first step, in this study, we will compare multi-model simulations from CMIP 5 with the FLUXNET observations at eight sites in which crops are grown. Note that the comprehensive evaluations not only are used to examine the limitations and deficiencies of the CMIP5 models without CGMs, but also help us to find out what kind of improvements that we can anticipate after the implementation of CGMs in ESMs. As most field crops are annuals, the biogeochemical and biogeophysical processes related to crop growth and development generally have strong seasonal and annual cycles. Hence we focus on the comparisons of simulated and observed annual cycles in gross primary production (GPP), net ecosystem product (NEP), terrestrial ecosystem respiration (TER), latent (HFLS) and sensible (HFSS) heat fluxes. The brief descriptions of the CMIP5 simulations and observational data as well as the statistics are given in section 2 . This will be followed by the result and discussion section. We will conclude our results on section 4 at last.

\section{MODELS, DATA AND METHOD}

The fifth phase of the coupled model intercomparison project (CMIP5) is a coordinated climate modeling experiments and most modeling groups worldwide have participated in it. ${ }^{23}$ Generally their simulations are used to assess national and international climate science. ${ }^{23}$ All models in CMIP5 do not have any process-based crop growth models and crop management ${ }^{24}$ some of them treat cropland similar as grassland with adjusted model parameters, others may just directly treat cropland as grassland without any modification or adjustment.

The CMIP5 monthly simulations including GPP, NEP, TER, HFLS, and HFSS are compared with the observations of the eddy-covariance FLUXNET towers. ${ }^{25}$ The model names and basic descriptions of model component configurations are listed in Table 1 . We also indicate if the model has crop plant function type (PFT) in its land or terrestrial biogeochemistry model components. Note that for the sake of convenience, a model family name is used to represent all models that are developed on the same institution but have different configurations on model components. For example, we use "the CESM1 model family" to represent CESM1BGC, CESM1-WACCM, CESM1-CAM5, and CCSM4, because all of them are derivatives of CESM1 with different configurations on the atmosphere, land, and biogeochemistry model components. Since GPP, NEP, and TER are highly related to biogeochemistry cycles, they denote biogeochemical variables hereafter, while latent and sensible heat fluxes are more related to the canopy physical processes and therefore denote biogeophysical variables hereafter.

Table 2 lists the names, locations and time periods of eight FLUXNET sites at which cropland is their major land cover. Five of them are from United States and three are from European. The crop types and irrigation practices at the sites are also shown in the table. There are four sites, all from U.S. (US-Ne1, US-Ne2, US-Ne3, and US-Bo1), in which cron and soybean are grown in one or two years rotation, while other four sites, one from United States and three from European (US-ARM, DE-Geb, DE-Kli, and DK-Ris), in which cereal crops are normally planted. For simplicity, the sites with corn and soybean planted are denoted by CORNSOY, and the sites with cereal crops planted are denoted by CEREAL.

Proc. of SPIE Vol. $9610961003-2$ 
Table 1. The names and brief descriptions of CMIP5 models (refer to http://es-doc.org/).

\begin{tabular}{lll} 
Model name & Brief desciption & Crop \\
\hline
\end{tabular}

\begin{tabular}{|c|c|c|}
\hline \multicolumn{3}{|l|}{ CESM } \\
\hline CCSM4 & $\begin{array}{l}\text { Includes the CAM4 atmopheric model and CLM4 land model, and is su- } \\
\text { perceded by CESM1 }\end{array}$ & $\mathrm{C}_{3} \& \mathrm{C}_{4}$ \\
\hline CESM1-BGC & Similar to CCSM4 but includs a full land \& ocean biogeochemistry cycle & $\mathrm{C}_{3} \& \mathrm{C}_{4}$ \\
\hline $\begin{array}{l}\text { CESM1- } \\
\text { WACCM }\end{array}$ & Similar to CCSM4 but uses the WACCM atmospheric model & $\mathrm{C}_{3} \& \mathrm{C}_{4}$ \\
\hline CESM1-CAM5 & Similar to CCSM4 but uses CAM5 atmospheric model & $\mathrm{C}_{3} \& \mathrm{C}_{4}$ \\
\hline \multicolumn{3}{|l|}{ HADLEY } \\
\hline HadCM3 & $\begin{array}{l}\text { Includes the MOSES1 land model with an interactive carbon cycle model, but } \\
\text { without dynamic vegetation model }\end{array}$ & None \\
\hline HADGEM2-ES & $\begin{array}{l}\text { Includes terrestrial carbon carbon cycle and dynamic vegetation model (TRIF- } \\
\text { FID) }\end{array}$ & None \\
\hline HADGEM2-CC & $\begin{array}{l}\text { Similar to HADGEM2-ES except for some physical schems and without inter- } \\
\text { active tropospheric chemistry module }\end{array}$ & None \\
\hline \multicolumn{3}{|c|}{ (1) } \\
\hline GFDL-CM3 & $\begin{array}{l}\text { Includes the CM3 climate model and LM3 land model with the global carbon } \\
\text { cycle }\end{array}$ & None \\
\hline GFDL-ESM2G & Similar to GFDL-CM3 expect for the CM2.1 climate model & None \\
\hline GFDL-ESM2M & $\begin{array}{l}\text { similar to GFDL-ESM2G but uses pressure-based vertical coordinations for its } \\
\text { ocean model }\end{array}$ & None \\
\hline \multicolumn{3}{|c|}{ (1) } \\
\hline MPI-ESM-LR & Includes the biogeochemical model HAMOCC & Yes \\
\hline MPI-ESM-MR & Same as MPI-ESM-LR but on medium resolution & Yes \\
\hline \multicolumn{3}{|c|}{ - } \\
\hline IPSL-CM5A-LR & $\begin{array}{l}\text { Includes terrestial \& ocean carbon cycle component and the ORCHIDEE land } \\
\text { model }\end{array}$ & $\mathrm{C}_{3} \& \mathrm{C}_{4}$ \\
\hline IPSL-CM5A-MR & Similar to IPSL-CM5A-LR but on the medium spatial resolution & $\mathrm{C}_{3} \& \mathrm{C}_{4}$ \\
\hline IPSL-CM5B-LR & Similar to IPSL-CM5A-LR but with different atmospheric physical parameters & $\mathrm{C}_{3} \& \mathrm{C}_{4}$ \\
\hline \multicolumn{3}{|c|}{ BCC } \\
\hline bcc-csm1-1 & Inlcudes AVIM land model with land and & Yes \\
\hline bcc-csm1-1-m & -1 but with a moderate resolution & Yes \\
\hline \multicolumn{3}{|l|}{ GISS } \\
\hline GISS-E2-R-CC & Includes Russell OGCM and carbon and biogeochemistry cylce & None \\
\hline GISS-E2-R & GISS-E-R-CC except for without carbon cycle and biogeochemistry & None \\
\hline GISS-E2-H-CC & Includes HYCOM OGCM and carbon cycle and biogeochemistry & None \\
\hline GISS-E2-H & reochemistry & None \\
\hline \multicolumn{3}{|l|}{ Others } \\
\hline MIROC-ESM & Includes dynamic vegetation and carbo & Yes \\
\hline CanESM2 & Includes dynamic vegetation and carbon cycle model (CTEM) & Yes \\
\hline MRI-ESM & Includes land \& ocean carbon cycle model & None \\
\hline CMCC-CESM & Includes carbon earth system model & Unknov \\
\hline inmcm4 & Includes land \& ocean biogeochemistry cycle & Unknow \\
\hline NorESM1-M & Originates from CCSM4 and includes CLM4 carbon \& nitrogen cycle & $\mathrm{C}_{3} \& \mathrm{C}_{4}$ \\
\hline CNRM-CM5 & $\begin{array}{l}\text { Inlcudes the ISBA land model and PISCES scheme as global carbon cycle } \\
\text { model }\end{array}$ & $\begin{array}{l}\text { Irrigated, } \\
\mathrm{C}_{3} \& \mathrm{C}_{4}\end{array}$ \\
\hline
\end{tabular}


Table 2. Eight FLUXNET cropland sites.

\begin{tabular}{lrrrlll}
\hline Site name Latitude & Longitude & Country & Data period & Crop type & $\begin{array}{l}\text { Irrigated } \\
\text { or rainfed? }\end{array}$ \\
\hline US-Bo1 $^{26}$ & 40.0062 & -88.2904 & $1996-2007$ & United States & cornEsoybean & rainfed \\
US-Ne1 $^{27}$ & 41.1651 & -96.4766 & $2001-2005$ & United States & corn Esoybean & irrigated \\
US-Ne2 $^{27}$ & 41.1649 & -96.4701 & $2001-2005$ & United States & cornEsoybean & irrigated \\
US-Ne3 $^{27}$ & 41.1797 & -96.4396 & $2001-2005$ & United States & cornEsoybean & rainfed \\
US-ARM $^{28}$ & 36.6058 & -97.4888 & $2003-2006$ & United States & cereal (wheat) & rainfed \\
DE-Geb $^{29}$ & 51.1001 & 10.9143 & $2004-2006$ & German & winter wheat / rapeseed / barley & unknown \\
& & & & & / sugar beet & \\
DE-Kli & 50.8929 & 13.5225 & $2004-2006$ & German & cereal & unknown \\
DK-Ris & 55.5303 & 12.0972 & $2004-2005$ & Denmark & cereal & unknown \\
\hline
\end{tabular}

As mentioned above, we focus on our evaluations on the annual cycles of the above biogeochemical and biogeophysical variables, therefore, the CMIP5 monthly simulations are interpolated into the locations of the sites using nearest neighbor method. The half-hourly FLUXNET data are averaged to the monthly data correspondingly. Temporal correlation coefficient with significance analysis and standard deviation are the major statistical metrics. All the metrics are calculated over the period in which the FLUXNET data are available (see Tab. 2) and account for both annual and inter-annual variations.

We first compare the climatology annual cycles of the CMIP5 simulations against FLUXNET observations to examine the model skills in simulating the phases and amplitudes of the annual cycles. Then we calculate the correlation coefficients and standard deviations between monthly CMIP5 simulations and FLUXNET observations. The statistics are illustratively shown in the Taylor Diagram ${ }^{30}$ as well as the centered root mean square errors (CRMSEs) with the overall time-means removed.

\section{RESULTS AND DISCUSSIONS}

\subsection{Climatology annual cycle}

Figure 1 shows the climatology annual cycles of the CMIP5 model simulations and FLUXNET observations. The observed GPPs over cropland generally have near-zero or very small negative values before and after a crop growing season (time between crop planting and harvesting dates) and reach their seasonal peaks in the middle of the season (Fig.1). Thus the GPP annual cycles are highly linked to the crop physiology and phenology and are expected to vary with different crops. For example, the observed GPP annual cycles at the CORNSOY sites are similar but largely differ from those at the CEREAL sites both in their phases and amplitudes, reflecting the different crop phenology for corn/soybean and cereal crops. The observed GPPs at the CORNSOY and CEREAL sites reach their seasonal peaks in summer and spring respectively (Fig.1). The models from same model families usually have very similar annual cycles with a little difference in the phases and amplitudes, but the differences among the models from different model families are usually large.

For the CORNSOY sites, the simulated annual cycles of most models, except the MPI and GFDL families, generally have their seasonal peaks 1-3 months earlier in phase and $0.01-0.21 \mathrm{mgCm}^{-2} \mathrm{~s}^{-1}$ smaller in magnitude than the observed cycles. Compared with other models, the MPI model family is best in simulating the GPP annual cycles. It could simulate the observed near-zero GPPs before and after a growing season, which most other models fail to reproduce. Moreover it catches the phases of the observed seasonal peaks for all four sites very well though it underestimates the magnitudes of the observed peaks by $0.01-0.13 \mathrm{mgCm}^{-2} \mathrm{~s}^{-1}$.

For the CEREAL sites, almost all models fail to catch the phases of the observed seasonal peaks and generally have 1-3 months later. Compared with other models, the IPSL model family has better performance overall. The annual cycles simulated by the IPSL-CM5B-LR at two German sites (DE-Geb and DE-Kli) have their seasonal maximum GPPs in June same as the observed peak month. Their magnitudes, however, are $0.05-0.09 \mathrm{mgCm}^{-2} \mathrm{~s}^{-1}$ larger than the observed GPPs after the seasonal peaks. 
The GPPs from the CESM1, BCC family and NorESM1-M are 7-9 times smaller than the observed GPPs for entire year. A possible reason is that these models may directly treat crop as grass without adjusting the model parameters related to the photosynthetic capacity. The models from the GISS model family, MRI-ESM1, and inmcm4 have almost identical annual cycles at all eight sites with different locations and crop types (Fig. 1). It indicates that the crop phenology for corn, soybean, and cereal crops is similar or same in these models. The reason may be that there is no crop PFTs in their land or carbon cycle models and the grass phenology is directly used over cropland. This approach likely leads to large biases in simulating biogeochemistry processes related to crop growth and development as different crops generally have largely different phenology and physiology.
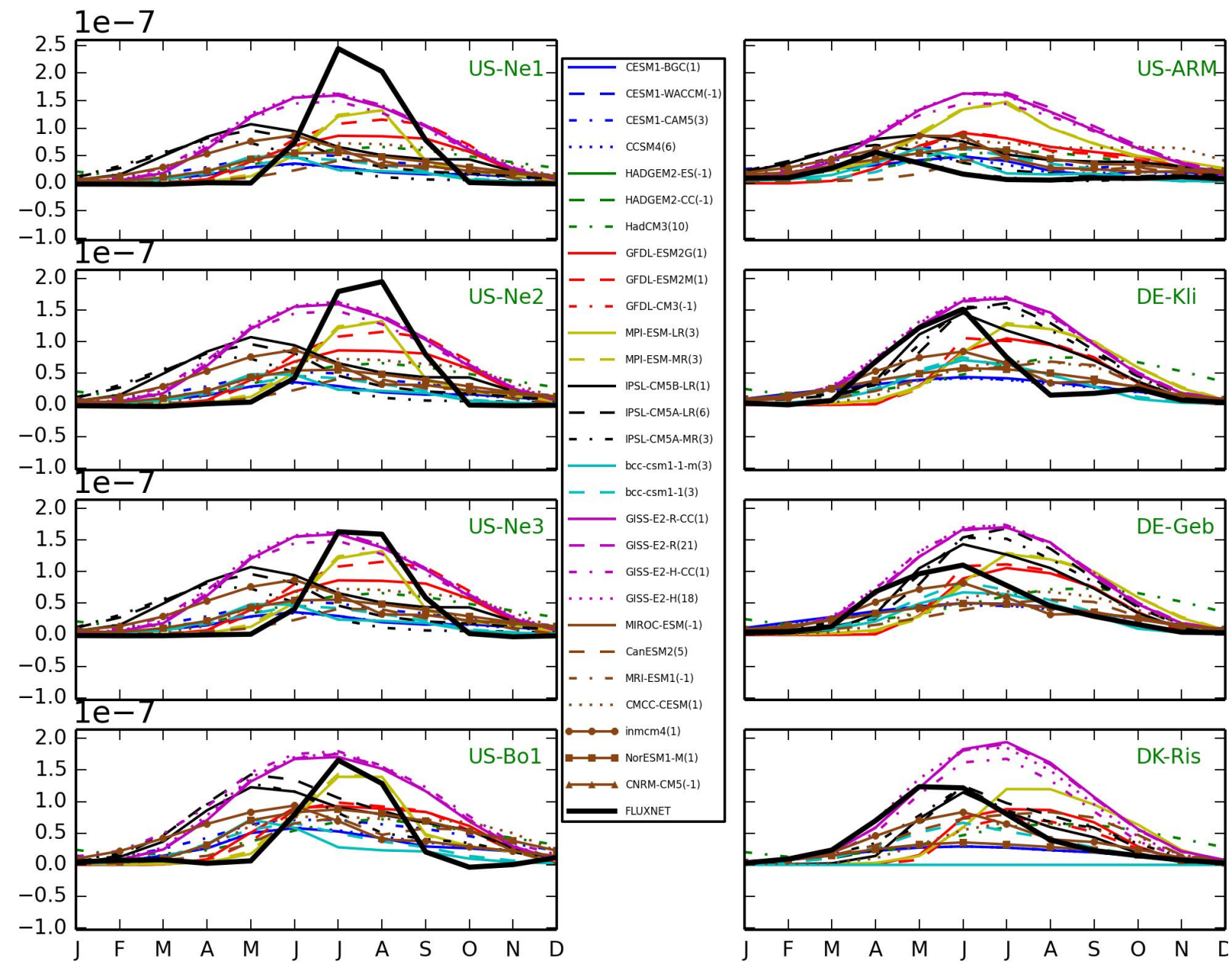

Figure 1. Climatology of annual cycles of the simulated (thin color lines) and observed (thick black solid line) gross primary production (unit: $\mathrm{kgCm}^{-2} \mathrm{~s}^{-1}$ ) at four CORNSOY sites (left panel) and four CEREAL sites (right panel). The number of model ensembles is shown in the curved bracket in the legend.

Fig. 2 shows the net ecosystem production (NEP). Similar to the results of the GPP, compared with other CMIP5 models, the simulated NEPs by the MPI and IPSL model families are in better agreement with the observed annual cycles both in phase and magnitude for the CRONSOY and CEREAL sites respectively. The MPI simulated peeks are only half of the observed NEP in magnitude, but the phase of the peaks agree well with the observations at the CRONSOY sites. In addition, MPI model family simulates near zero NEPs during spring that is a little larger than the observed NEPs, however it simulates negative NEPs (about 0.01-0.02 $\mathrm{mgCm}^{-2} \mathrm{~s}^{-1}$ ) that agree well with the observed NEPs during fall. The simulations from the IPSL models at the CEREAL sites are reasonably consistent to the observations, but the IPSL models overestimate NEPs by $0.01-0.04 \mathrm{mgCm}^{-2} \mathrm{~s}^{-1}$ and underestimate NEPs by $0.02-0.06 \mathrm{mgCm}^{-2} \mathrm{~s}^{-1}$ before and after the peaks respectively. We can get the similar 
results by comparing the simulated and observed terrestrial ecosystem respiration (TER) (Fig. 3). Note that the simulated TERs of MRI-ESM1 are much larger than those of other models and observations at all sites.

As mentioned in the section 2, all models in CMIP5 did not have process-based crop growth models and they generally adjust the model parameters on the basis of the observations acquired from certain crop type field. Form the above comparisons on the biogeochemical variables at different crop type sites, the models that directly apply grass phenology for crop have large biases in the phases and amplitudes of annual cycles at all sites. Even though the models with tuned parameters including the MPI and IPSL model family may have good skills over some croplands, the skills are highly dependent on the crop types of the croplands in which the model parameters are tuned using the observed data.
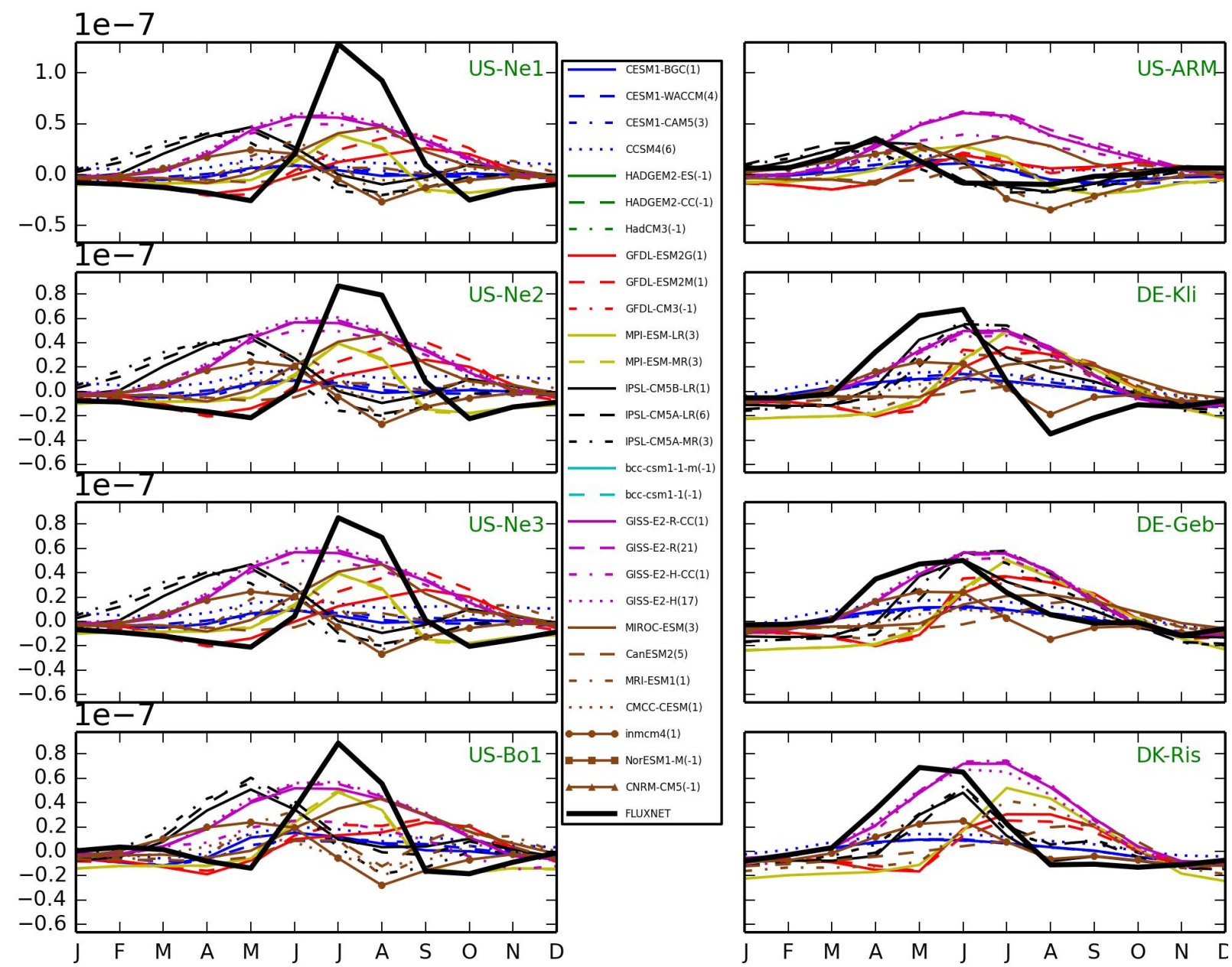

Figure 2. Same as Fig.1, except for net ecosystem production (NEP) whose unit is $\mathrm{kgCm}^{-2} \mathrm{~s}^{-1}$ ).

For the CORNSOY sites, the peak phases (magnitudes) of the observed latent heat fluxes are August (120-130 $\left.\mathrm{Wm}^{-2}\right)$ at $\mathrm{Ne} 1, \mathrm{Ne} 2$, and $\mathrm{Ne} 3$, and July $\left(102 \mathrm{Wm}^{-2}\right)$ at Bo1 respectively. The simulated annual cycles of MPI model family generally agree well with the FLUXNET observations, except have $15-26 \mathrm{Wm}^{-2}$ overestimations before and after the seasonal peak. The peaks of all other CMIP5 models normally occur in one-month earlier and their magnitudes agree well with the observed peaks at all sites except Bo1 at which the simulated peak magnitudes are 10-50 $\mathrm{Wm}^{-2}$ larger (Fig. 4). For CEREAL sites, the observed peaks occur in April at US-ARM, June at DE-Kli and DE-Geb, and May at DK-Ris respectively(Fig. 4), while the CMIP5 simulated peaks are found in 1-5 months later and 11-87 $\mathrm{Wm}^{-2}$ larger for all sites. The CMIP5 models have very different annual cycles at DK-Ris, some models including the CESM1, GISS, IPSL, and BCC model families have the peaks 

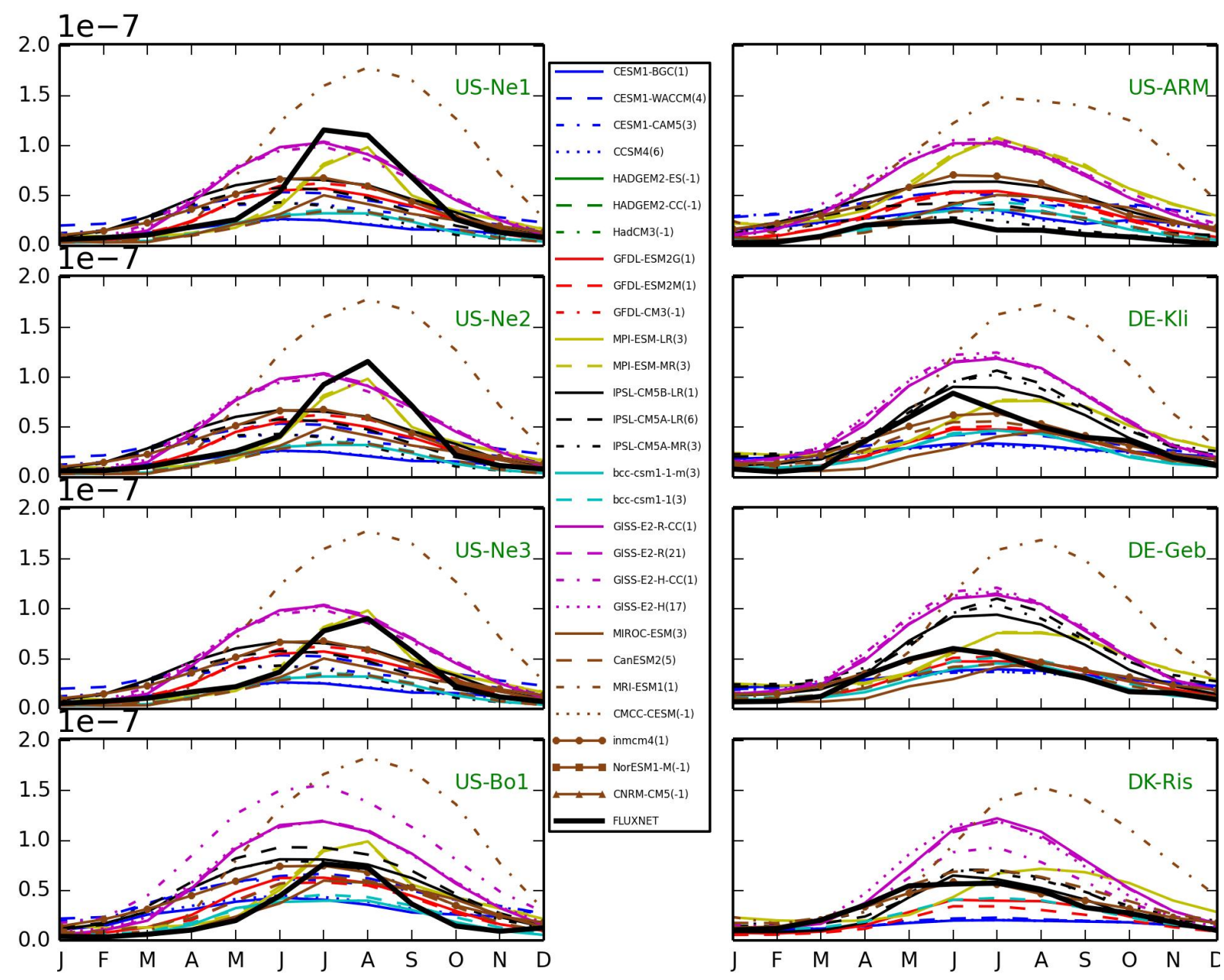

Figure 3. Same as Fig.1, except for terrestrial ecosystem respiration (TER) whose unit is $\mathrm{kgCm}^{-2} \mathrm{~s}^{-1}$.

during fall, while other models have the peaks during summer. This may be due to the different land covers defined in these models.

There are two peaks in the annual cycles of observed sensible heat fluxes at the CORNSOY sites, arising in May and October (Fig.5). The two-peak pattern over corn and soybean field has been reported by other researchers. ${ }^{21,31}$ All CMIP5 models miss the observed two peaks of sensible heat fluxes except for the CESM1 model family that has two weak peaks but their phases and magnitudes are not in agreement with the observations. Note that compared with other variables, the differences of the sensible heat fluxes simulated by the model members of the CESM1 model family are larger. For example, the simulated sensible heat fluxes by CESM1-BGC and CCSM4 are nearly identical, but they are $10-20 \mathrm{Wm}^{-2}$ and $31-42 \mathrm{Wm}^{-2}$ less than the simulations of CESM1-CAM5 and CESM1-WACCM respectively. The MPI model family has best skills in simulating the annual cycles of biogeochemical variables (GPP, NEP and TER) and latent heat fluxes as compared with other models. But it simulates a very weak annual cycle of sensible heat flux with a flat and low peak that is less than $30 \mathrm{Wm}^{-2}$ and lasts for 7 months. It indicates that although the models without processed-based crop growth models can adjust some model parameters to improve their skills on certain variables over cropland, they may still have very large biases for other related variables due to the inconsistency of model components and parameters during the model calibrating and tuning processes.

The two-peak pattern is not obvious in the observed sensible heat fluxes at the CEREAL sites (Fig. 5). Except at DE-Ris the simulated annual cycles of the BCC model family are in good agreement with the observed 
peak in phase but are 12-32 $\mathrm{Wm}^{-2}$ larger in magnitudes. Other models generally have 1-2 months later and 2-3 months earlier in the phases of the simulated annual cycles for US-ARM, DE-Kli and DE-Geb respectively.
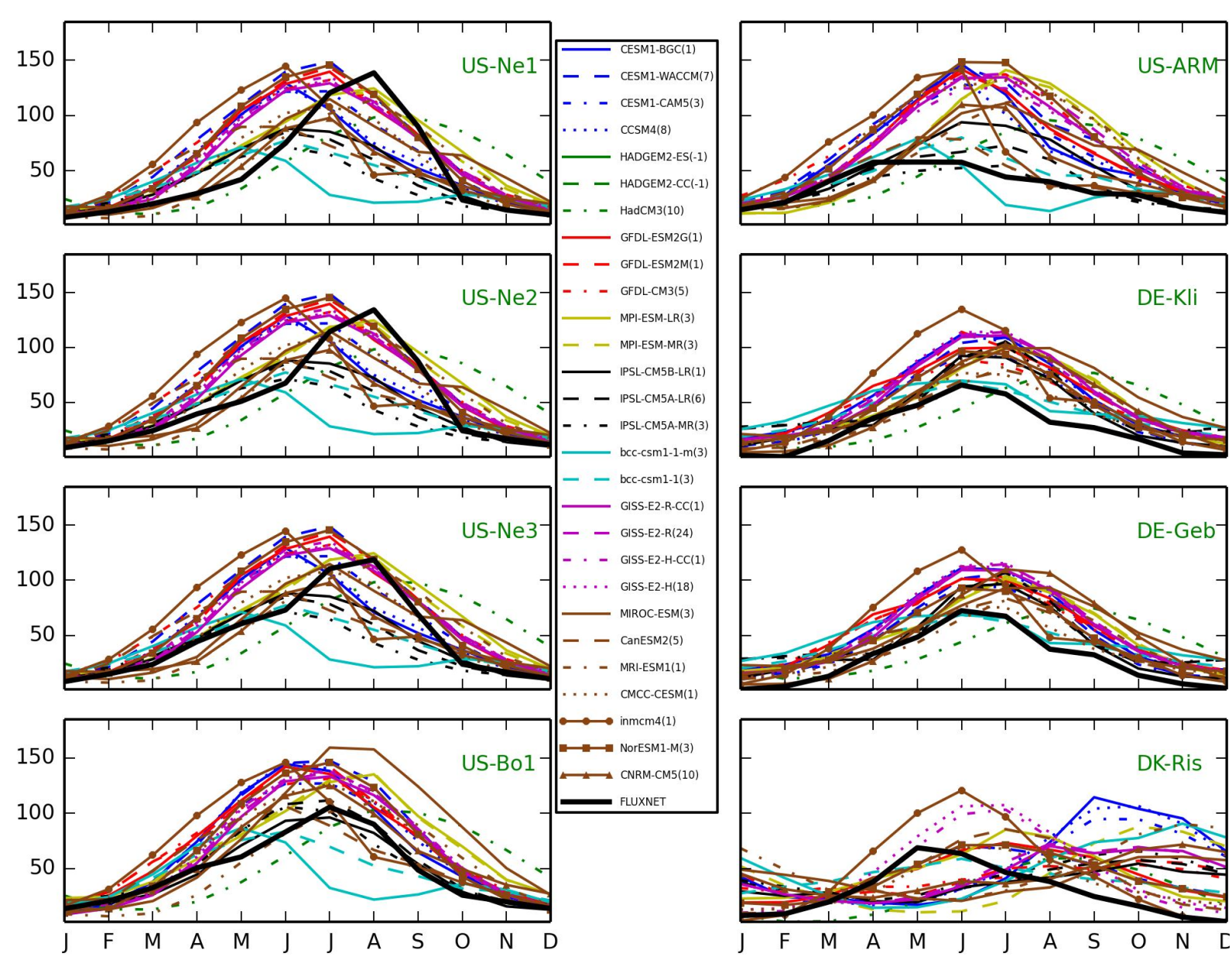

Figure 4. Same as Fig.1, except for latent heat flux whose unit is $\mathrm{Wm}^{-2}$.

\subsection{Statistical analysis}

Fig.6 is the Taylor Diagrams for the simulated GPPs over two CRONSOY sites (US-Ne1 and US-Bo1, left panel) and two CEREAL sites (US-ARM and DE-Kli, right panel). The MPI model family has better performance in GPP simulations at the CRONSOY sites than other models with largest and significant correlation coefficients (0.84 and 0.81 for US-Ne1 and US-Bo1) at a $90 \%$ confidence level and smallest CRMSEs. Its skills in standard deviation (variation), however, is worse than the GISS model family and simulated variations are $20 \%$ less than the observed variations. At the CEREAL sites, the simulated GPPs by the ISPL model family are significantly correlated with the observed GPPs and the simulated and observed variations are in a good agreement. The CESM1 model family generally has smallest variation both at the CORNSOY and CEREAL sites compared with other models. We can see the similar results from the Taylor Diagrams for NEP and TER (figures are not shown).

Figures 7 and 8 are the Taylor Diagrams for simulated latent and sensible heat fluxes respectively. The CMIP5 models normally have better skills in the latent heat fluxes than the biogeochemical variables at all sites (Fig. 7). The correlation coefficients of the MPI, CESM1, GFDL, and IPSL model families are almost identical and all of them are significant at a $90 \%$ confidence level. They are $0.81,0.72,0.88$, and 0.85 at US-Ne1, US-ARM, 

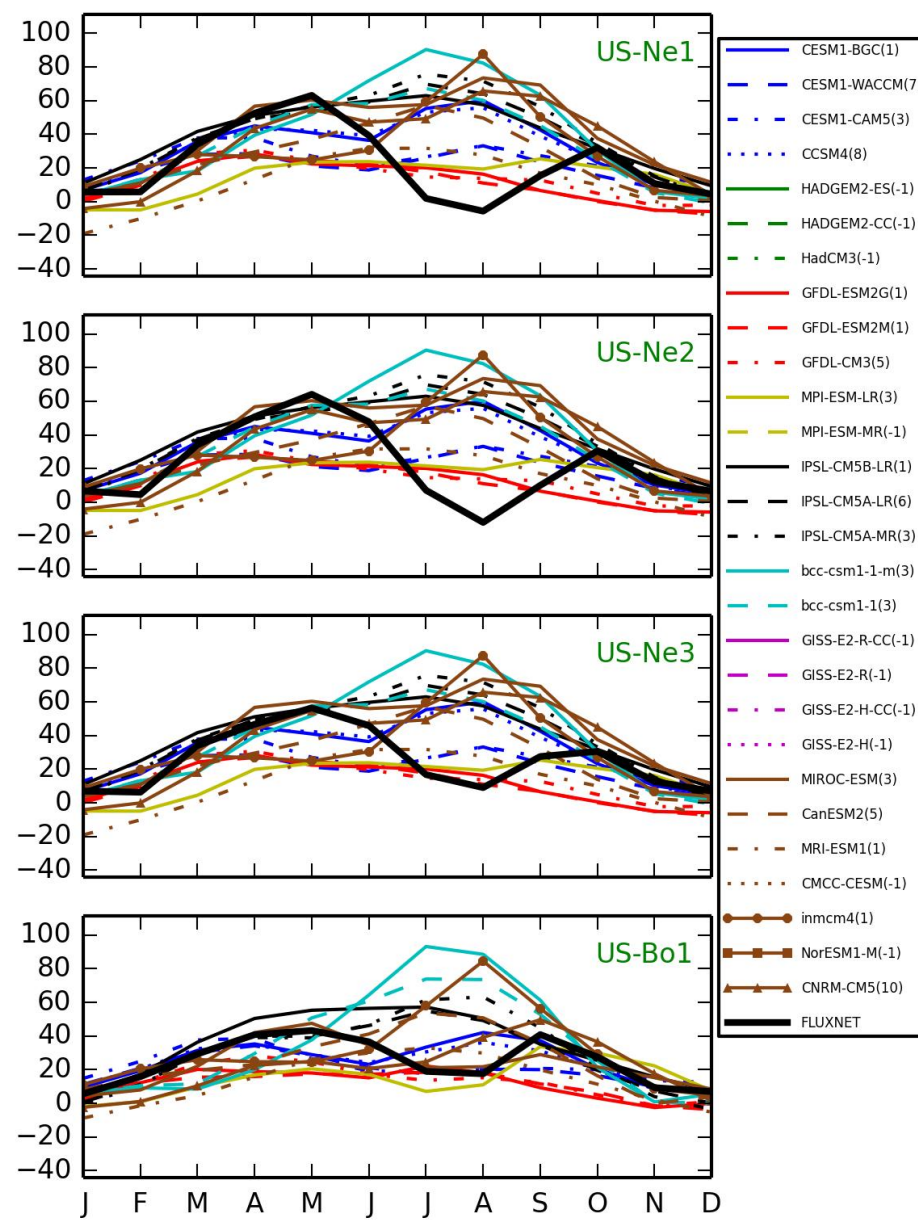
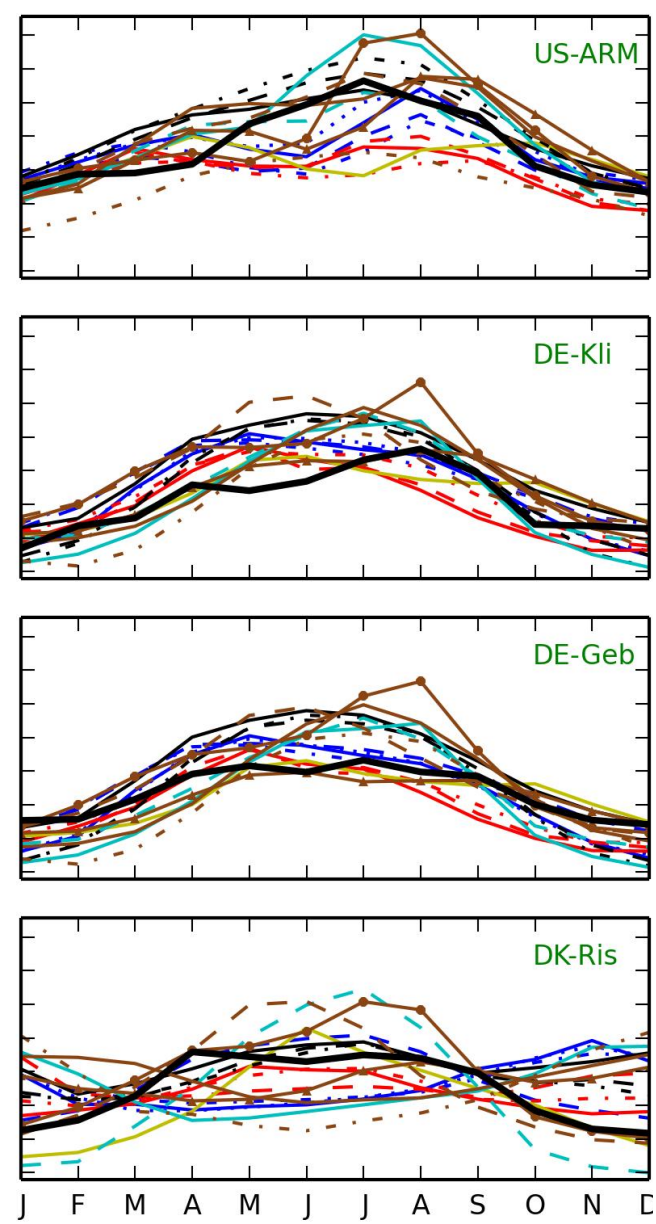

Figure 5. Same as Fig.1, except for sensible heat flux whose unit is $\mathrm{Wm}^{-2}$.

US-Bo1, and DE-Kli respectively. While for the sensible heat fluxes over the CORNSOY sites, the correlation coefficients of all models are less than 0.6 as all models miss the observed two-peak patten. At the CEREAL sites, the correlation coefficients are generally larger than those at the CORNSOY sites. The IPSL, BCC and CESM1 overall have better performances.

\section{CONCLUSIONS}

Cropland plays an important role in global carbon cycle and is a highly managed land with many human activities. It is essential to study the response and feedback of cropland to future global and regional climate and variability in order to mitigate the increases of future carbon emission and secure the food and fibre supply for a growing global population. The interactions between cropland and atmosphere, however, generally involve complex biogeophysical and biogeochemical processes and remain large uncertainties. In this study, we address the uncertainties by evaluating the limitations and deficiencies of the CMIP5 simulations over cropland. The results show that:

1. Most CMIP5 models have unsatisfactory skills in the annual cycles of the biogeochemical and biogeophysical variables and the observed and simulated annual cycles generally generally are not consistent in either phase or amplitude. 

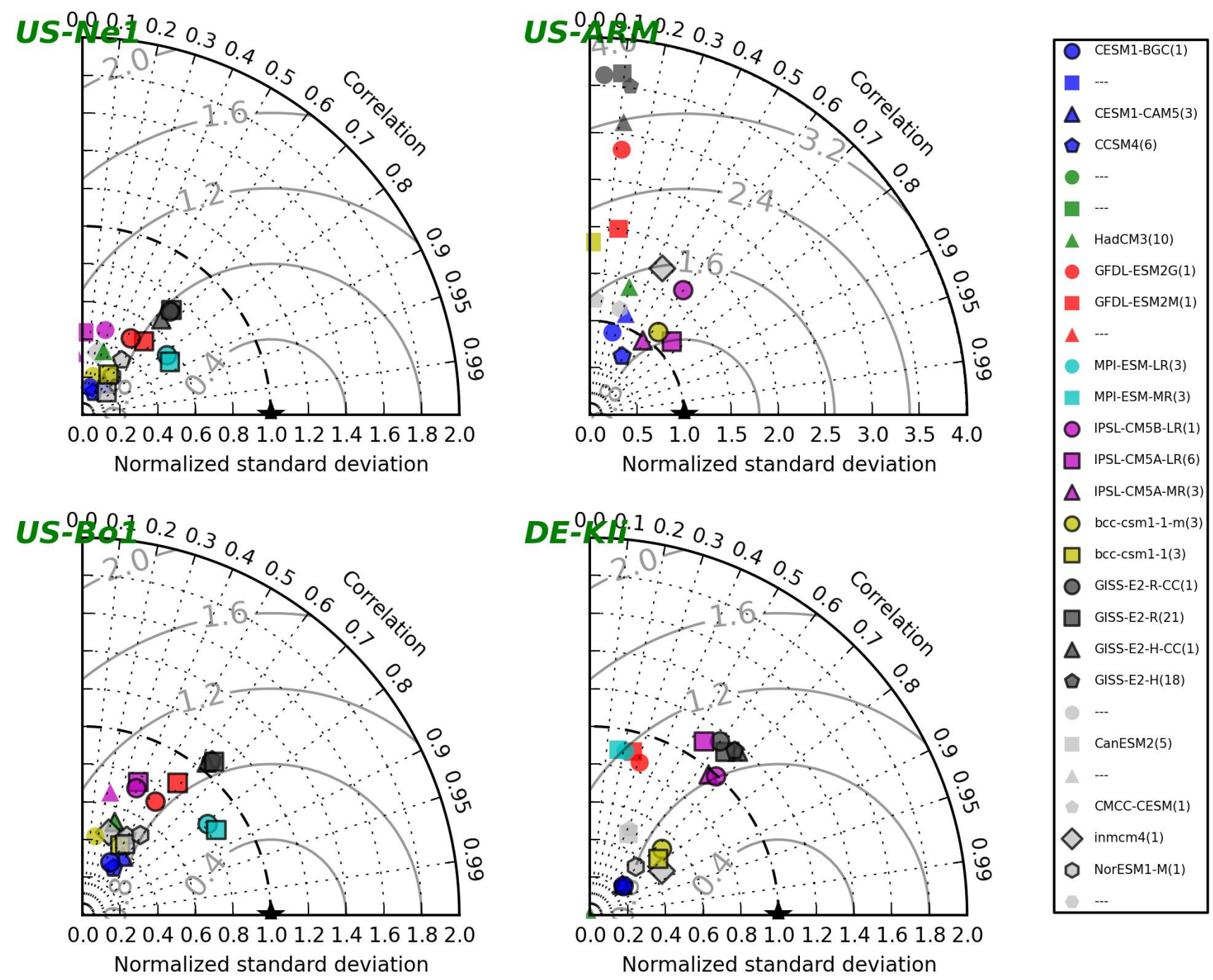

Figure 6. Taylor diagram for the GPPs over two CRONSOY sites (US-Ne1 and US-Bo1, left panel) and two CEREAL sites (US-ARM and Deb-Kli, right panel). The symbols circling by a black line represent the correlations between the simulations and observations are significant at a $90 \%$ confidence level. 


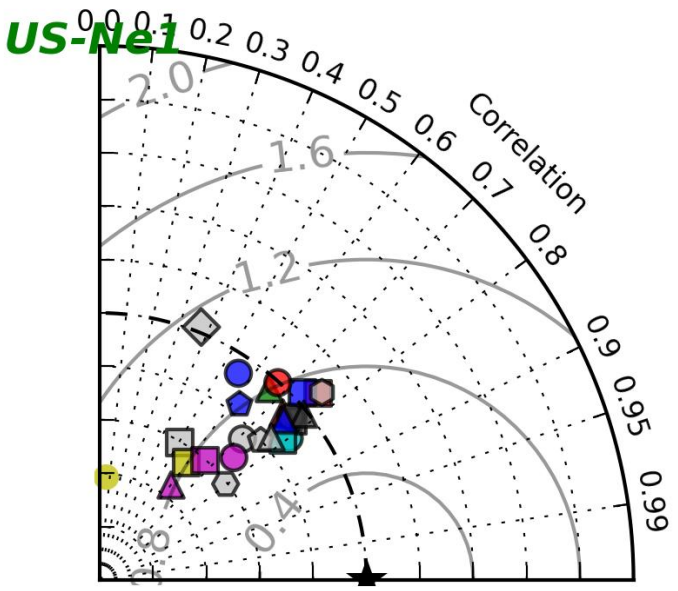

0.00 .20 .40 .60 .81 .01 .21 .41 .61 .82 .0

Normalized standard deviation



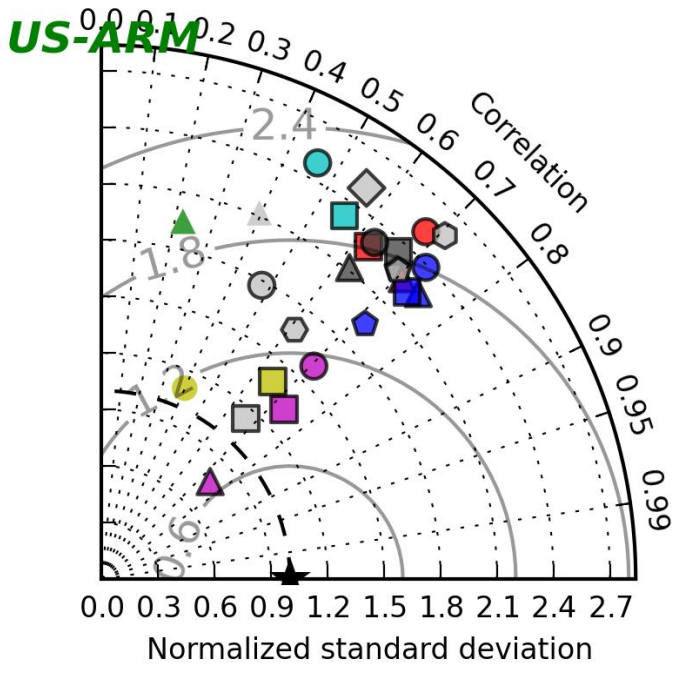

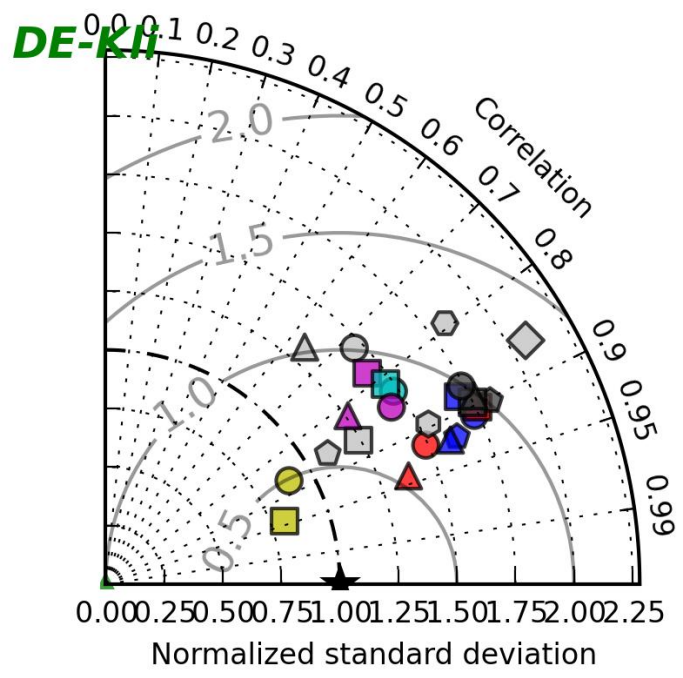

\begin{tabular}{|c|c|}
\hline $\bar{O}$ & CESM1-BGC(1) \\
\hline$\square$ & CESM1-WACCM(7) \\
\hline$\Delta$ & CESM1-CAM5(3) \\
\hline$\Delta$ & CCSM4(8) \\
\hline - & --- \\
\hline 口 & -- \\
\hline $\boldsymbol{\Delta}$ & $\operatorname{HadCM} 3(10)$ \\
\hline 0 & GFDL-ESM2G(1) \\
\hline$\square$ & GFDL-ESM2M(1) \\
\hline$\Delta$ & GFDL-CM3(5) \\
\hline 0 & MPI-ESM-LR(3) \\
\hline$\square$ & MPI-ESM-MR(3) \\
\hline 0 & IPSL-CM5B-LR(1) \\
\hline$\square$ & IPSL-CM5A-LR(6) \\
\hline$\Delta$ & IPSL-CM5A-MR(3) \\
\hline 0 & bcc-csm 1-1-m(3) \\
\hline$\square$ & bcc-csm1-1(3) \\
\hline 0 & GISS-E2-R-CC(1) \\
\hline$\square$ & GISS-E2-R(24) \\
\hline$\Delta$ & GISS-E2-H-CC(1) \\
\hline 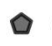 & GISS-E2-H(18) \\
\hline 0 & MIROC-ESM(3) \\
\hline$\square$ & CanESM2(5) \\
\hline$\Delta$ & MRI-ESM1(1) \\
\hline$\Delta$ & CMCC-CESM(1) \\
\hline$\diamond$ & inmcm4(1) \\
\hline 0 & NorESM1-M(3) \\
\hline 0 & CNRM-CM5(10) \\
\hline
\end{tabular}

Figure 7. Same as Fig.6, except for latent heat flux 


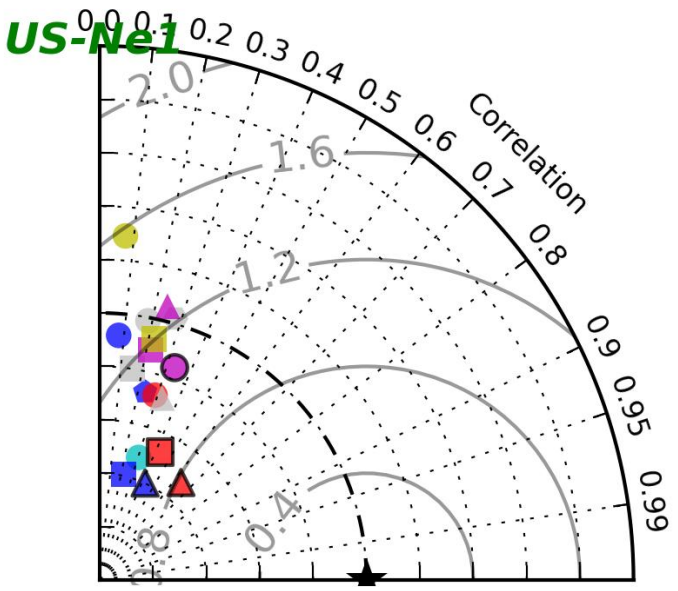

0.00 .20 .40 .60 .81 .01 .21 .41 .61 .82 .0

Normalized standard deviation



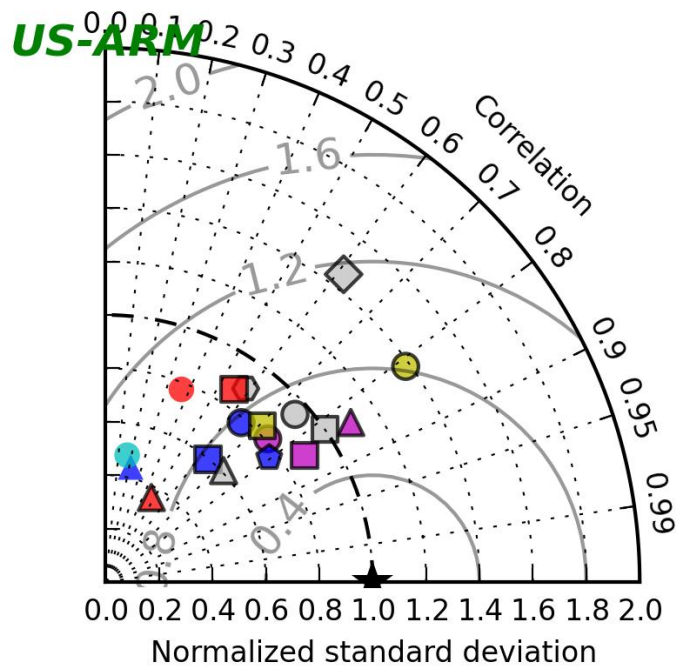

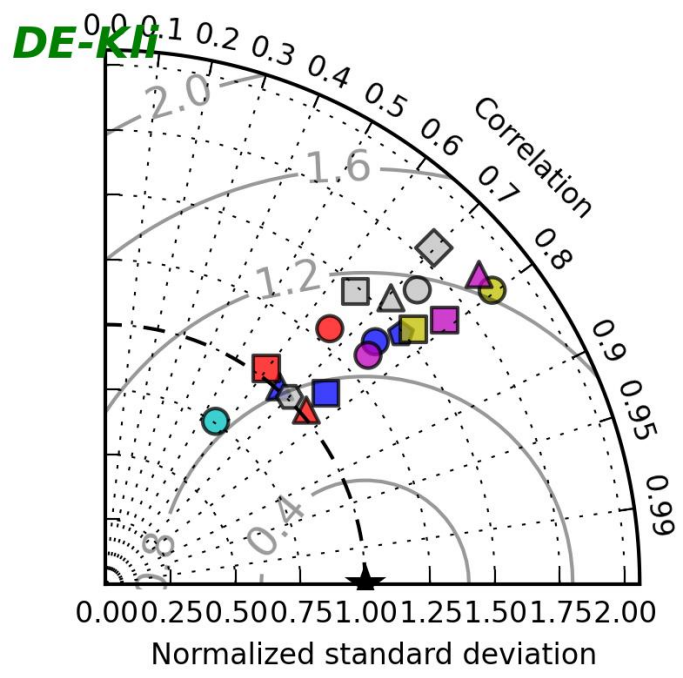

\begin{tabular}{|c|c|}
\hline$\overline{7}$ & CESM1-BGC(1) \\
\hline$\square$ & CESM1-WACCM(7) \\
\hline$\triangle$ & CESM1-CAM5(3) \\
\hline 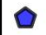 & $\operatorname{CCSM} 4(8)$ \\
\hline ? & --- \\
\hline$\square$ & --- \\
\hline $\mathbf{\Delta}$ & --- \\
\hline 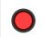 & GFDL-ESM2G(1) \\
\hline ت & GFDL-ESM2M(1) \\
\hline$\Delta$ & GFDL-CM3(5) \\
\hline 0 & MPI-ESM-LR(3) \\
\hline$\square$ & --- \\
\hline 0 & IPSL-CM5B-LR(1) \\
\hline ᄃ & IPSL-CM5A-LR(6) \\
\hline$\Delta$ & IPSL-CM5A-MR(3) \\
\hline 0 & bcc-csm1-1-m(3) \\
\hline$\square$ & bcc-csm1-1(3) \\
\hline 0 & -- \\
\hline D & --- \\
\hline$\Delta$ & -- \\
\hline 뭄 & --- \\
\hline 0 & MIROC-ESM(3) \\
\hline$\square$ & CanESM2(5) \\
\hline$\Delta$ & MRI-ESM1(1) \\
\hline 담 & -- \\
\hline 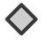 & inmcm4(1) \\
\hline 0 & -- \\
\hline 0 & CNRM-CM5(10) \\
\hline
\end{tabular}

Figure 8. Same as Fig.6, except for sensible heat flux 
2. Compared with other models, the MPI and IPSL model families have better skills in modeling surface biogeochemical fluxes at the corn/soybean and cereal crop sites respectively.

3. None of the CMIP5 models successfully simulate the observed two-peak pattern in the annual cycles of sensible heat fluxes at the corn/soybean sites. Though the simulated annual cycles of the CESM1 model family have two weak peaks, their peaks are different to the observed peaks both in phase and magnitude.

4. The simulated GPPs and NEPs of the CESM1, BCC model families and NorESM1-M are much smaller than the observations for entire year. A possible reason is that these models may directly treat crop as grass without adjusting the model parameters related to the photosynthetic capacity.

5. Model members from same model family normally simulate similar annual cycles both in phase and magnitude, but the model members from the CESM1 model family with different atmospheric models have largely different annual cycles.

6. The biases both in phases and magnitudes of annual cycles for the biogeochemical variables (GPP, NEP and TER) are generally larger than those biogeophysical variables (sensible and latent heat fluxes).

None of the CMIP5 models can have a reasonable skill both at the corn/soybean and cereal crop sites as they simulate the biogeochemical and biogeophysical processes over cropland using tuned parameters for grassland instead of process-based crop growth models. As such it is essential to implement crop growth models into ESMs to better represent the crop physiology and phenology and improve the model skills over cropland. In the future, we plan to assess the performance of the ESMs with process-based crop growth models over cropland.

\section{ACKNOWLEDGMENTS}

This research was supported by the Biogeochemistry-Climate Feedbacks Scientific Focus Area project funded through the Regional and Global Climate Modeling Program in Climate and Environmental Sciences Division (CESD) of the Biological and Environmental Research (BER) Program in the U.S. Department of Energy Office of Science. We are grateful to the World Climate Research Program's Working Group on Coupled Modeling and the worldwide climate modeling groups for making CMIP5 data publicly available. This work used eddy-covariance data acquired by the FLUXNET community from the ORNL CDIAC website (http://cdiac.ornl.gov/). We appreciate the site PIs of US-Ne1, US-Ne2, US-Ne3, US-Bo1, US-ARM, DE-Geb, DE-Kli and DK-Ris. We thank the International Land Model Benchmarking (ILAMB) project for providing the state-of-art model evaluation tools written in Python. We also thank our colleagues Drs. Nathaniel Collier and Jitendra Kumar for their constructive suggestions. The views expressed are those of the authors and do not necessarily reflect those of sponsoring agencies.

\section{REFERENCES}

[1] Burdyuzha, V. and Khozin, G. S., eds., [The future of the universe and the future of our civilization: Budapest-Debrecen, Hungary, 2-6 July 1999], World Scientific, Singapore ; River Edge, N.J (2000).

[2] Tubiello, F. N., Soussana, J.-F., and Howden, S. M., "Crop and pasture response to climate change," Proceedings of the National Academy of Sciences 104, 19686 -19690 (Dec. 2007).

[3] Lubowski, R. N. et al., [Major uses of land in the United States, 2002], United States, Dept. of Agriculture, Economic Research Service (2006).

[4] Liang, X.-Z., Xu, M., Gao, W., Reddy, K. R., Kunkel, K., Schmoldt, D. L., and Samel, A. N., "Physical Modeling of U.S. Cotton Yields and Climate Stresses during 1979 to 2005," Agronomy Journal 104(3), 675-683 (2012).

[5] Betts, R. A., "Integrated approaches to climateâĂŞcrop modelling: needs and challenges," Philosophical Transactions of the Royal Society B: Biological Sciences 360, 2049-2065 (Nov. 2005).

[6] Tilman, D., Balzer, C., Hill, J., and Befort, B. L., "Global food demand and the sustainable intensification of agriculture," Proceedings of the National Academy of Sciences 108, 20260-20264 (Dec. 2011). 
[7] Ray, D. K., Mueller, N. D., West, P. C., and Foley, J. A., "Yield Trends Are Insufficient to Double Global Crop Production by 2050," PLoS ONE 8, e66428 (June 2013).

[8] Alexandratos, N., Bruinsma, J., et al., "World agriculture towards 2030/2050: the 2012 revision," ESA Work. Pap 3 (2012).

[9] Watson, R., Noble, I., Bolin, B., Ravindranath, N., Verardo, D., and Dokken, D., eds., [Intergovernmental Panel on Climate Change (2000) Special Report on Emissions Scenarios. A Special Report of Working Group III of the Intergovernmental Panel on Climate Change], Cambridge Univ Press, Cambridge UK (2000).

[10] Lal, R., "Soil carbon sequestration impacts on global climate change and food security," science 304(5677), 1623-1627 (2004).

[11] Smith, P., Martino, D., Cai, Z., Gwary, D., Janzen, H., Kumar, P., McCarl, B., Ogle, S., O’Mara, F., Rice, C., et al., "Greenhouse gas mitigation in agriculture," Philosophical Transactions of the Royal Society B: Biological Sciences 363(1492), 789-813 (2008).

[12] Janssens, I. A., Freibauer, A., Ciais, P., Smith, P., Nabuurs, G.-J., Folberth, G., Schlamadinger, B., Hutjes, R. W. A., Ceulemans, R., Schulze, E.-D., Valentini, R., and Dolman, A. J., "Europe's Terrestrial Biosphere Absorbs 7 to $12 \%$ of European Anthropogenic CO2 Emissions," Science 300, 1538-1542 (June 2003).

[13] Metz, B., Davidson, O., Bosch, P., Dave, R., and Meyer, L., [Mitigation of climate change], Cambridge University Press Cambridge (2007).

[14] Olesen, J. E., Carter, T., Diaz-Ambrona, C., Fronzek, S., Heidmann, T., Hickler, T., Holt, T., Minguez, M., Morales, P., Palutikof, J., et al., "Uncertainties in projected impacts of climate change on european agriculture and terrestrial ecosystems based on scenarios from regional climate models," Climatic Change 81(1), 123-143 (2007).

[15] Lobell, D. B. and Burke, M. B., "Why are agricultural impacts of climate change so uncertain? the importance of temperature relative to precipitation," Environmental Research Letters 3(3), 034007 (2008).

[16] Xu, M., Liang, X.-Z., Gao, W., Reddy, K. R., Slusser, J., and Kunkel, K., "Preliminary results of the coupled CWRF-GOSSYM system," in [Remote Sensing and Modeling of Ecosystems for Sustainability II], Gao, W. and Shaw, D. R., eds., 5884, 588409, SPIE (2005).

[17] Osborne, T., Lawerence, D. M., Challinor, A. J., Slingo, J. M., and Wheeler, T. R., "Development and assessment of a coupled cropâĂŞclimate model," Global Change Biology 13(1), 169-183 (2007).

[18] Xu, M., Liang, X., and Gao, W., "Implementation of DSSAT CERES-maize model in CWRF and off-line preliminary results," AGU Fall Meeting Abstracts -1, 0991 (Dec. 2009).

[19] Liang, X.-Z., Xu, M., Gao, W., Reddy, K. R., Kunkel, K., Schmoldt, D. L., and Samel, A. N., "A Distributed Cotton Growth Model Developed from GOSSYM and Its Parameter Determination," Agronomy Journal 104(3), 661-674 (2012).

[20] Levis, S., Bonan, G. B., Kluzek, E., Thornton, P. E., Jones, A., Sacks, W. J., and Kucharik, C. J., "Interactive Crop Management in the Community Earth System Model (CESM1): Seasonal Influences on LandâĂŞAtmosphere Fluxes," Journal of Climate 25, 4839-4859 (July 2012).

[21] Chen, M., Griffis, T. J., Baker, J., Wood, J. D., and Xiao, K., "Simulating crop phenology in the Community Land Model and its impact on energy and carbon fluxes: Evaluation of CLM crop simulations," Journal of Geophysical Research: Biogeosciences 120, 310-325 (Feb. 2015).

[22] Lu, Y., Jin, J., and Kueppers, L. M., "Crop growth and irrigation interact to influence surface fluxes in a regional climate-cropland model (WRF3.3-CLM4crop)," Climate Dynamics , 1-17 (Mar. 2015).

[23] Taylor, K. E., Stouffer, R. J., and Meehl, G. A., "An Overview of CMIP5 and the Experiment Design," Bulletin of the American Meteorological Society 93, 485-498 (Apr. 2012).

[24] Guanter, L., Zhang, Y., Jung, M., Joiner, J., Voigt, M., Berry, J. A., Frankenberg, C., Huete, A. R., Zarco-Tejada, P., Lee, J.-E., Moran, M. S., Ponce-Campos, G., Beer, C., Camps-Valls, G., Buchmann, N., Gianelle, D., Klumpp, K., Cescatti, A., Baker, J. M., and Griffis, T. J., "Global and time-resolved monitoring of crop photosynthesis with chlorophyll fluorescence," Proceedings of the National Academy of Sciences 111, E1327-E1333 (Apr. 2014). 
[25] Baldocchi, D., Falge, E., Gu, L., Olson, R., Hollinger, D., Running, S., Anthoni, P., Bernhofer, C., Davis, K., Evans, R., Fuentes, J., Goldstein, A., Katul, G., Law, B., Lee, X., Malhi, Y., Meyers, T., Munger, W., Oechel, W., Paw, K. T., Pilegaard, K., Schmid, H. P., Valentini, R., Verma, S., Vesala, T., Wilson, K., and Wofsy, S., "FLUXNET: A New Tool to Study the Temporal and Spatial Variability of EcosystemâASŞScale Carbon Dioxide, Water Vapor, and Energy Flux Densities," Bulletin of the American Meteorological Society 82, 2415-2434 (Nov. 2001).

[26] Meyers, T. P., "A comparison of summertime water and $\mathrm{CO} 2$ fluxes over rangeland for well watered and drought conditions," Agricultural and Forest Meteorology 106, 205-214 (Feb. 2001).

[27] Verma, S. B., Dobermann, A., Cassman, K. G., Walters, D. T., Knops, J. M., Arkebauer, T. J., Suyker, A. E., Burba, G. G., Amos, B., Yang, H., Ginting, D., Hubbard, K. G., Gitelson, A. A., and Walter-Shea, E. A., "Annual carbon dioxide exchange in irrigated and rainfed maize-based agroecosystems," Agricultural and Forest Meteorology 131, 77-96 (July 2005).

[28] Fischer, M. L., Billesbach, D. P., Berry, J. A., Riley, W. J., and Torn, M. S., "Spatiotemporal Variations in Growing Season Exchanges of CO2, H2o, and Sensible Heat in Agricultural Fields of the Southern Great Plains," Earth Interactions 11, 1-21 (Oct. 2007).

[29] Anthoni, P. M., Knohl, A., Rebmann, C., Freibauer, A., Mund, M., Ziegler, W., Kolle, O., and Schulze, E.-D., "Forest and agricultural land-use-dependent CO2 exchange in Thuringia, Germany," Global Change Biology 10, 2005-2019 (Dec. 2004).

[30] Taylor, K. E., "Summarizing multiple aspects of model performance in a single diagram," Journal of Geophysical Research: Atmospheres 106, 7183-7192 (Apr. 2001).

[31] Kumar, S. and Merwade, V., "Evaluation of NARR and CLM3.5 outputs for surface water and energy budgets in the Mississippi River Basin," Journal of Geophysical Research 116 (Apr. 2011). 